\title{
ALGUMAS REFLEXÕES SOBRE O PROCESSO DE ENSINO/APRENDIZAGEM DE LÍNGUAS E LITERATURAS
}

\author{
Izabel F. O. Brandão \\ Programa de Pós-Graduação em Letras \\ Universidade Federal de Alagoas
}

De maneira geral, o ensino de línguas sempre funcionou divorciado das literaturas. A abordagem ao texto literário, se (e quando) feita, normalmente tem sua base no uso de textos simplificados ou da estilistica. ${ }^{1} \dot{E}$ bem possivel que isto se adeqüe mais ao ensino de linguas estrangeiras do que propriamente ao ensino da língua materna. Entretanto, a prática de sala de aula mostra o distanciamento das literaturas quando se trata do ensino de línguas, seja a materna ou qualquer outra (e aqui não me refiro exclusivamente ao ensino das línguas estrangeiras modernas). Quando se trata do uso de textos simplificados ou textos prontos, escritos especificamente para um determinado contexto de ensino de línguas, o texto literário simplesmente deixa de ser um texto autêntico para funcionar meramente como uma ferramenta de aprendizagem de vocabulário ou de algum item gramatical. ${ }^{2}$ No tocante à estilística, a situação é um pouco mais complexa. E mesmo atestando a validade desse tipo de abordagem para propósitos lingüísticos, a estilística, se utilizada inadequadamente, pode se transformar num imenso obstáculo no processo de ensino da literatura, especialmente no que se refere à motivação do/a aluno/a.

Um resumo deste ensaio foi publicado nos Anais da $46 a$. Reunião anual da SBPC (Vitória, ES, jul. 1994). Cf B.10, p. 493. Outra versão deste artigo em inglês está sendo publicada na Revista Ilha do Desterro, n. 37 , jul./dez. 1999, da PG Inglês da UFSC, em um número intitulado The challenge of literature and foreign language teaching and learning.

2 Cf. Brumfit e Carter (1987). Para a referência completa, ver final deste trabalho. 
Um fator, entre outros, que funciona como um elemento complicador no divórcio entre o ensino de línguas e literaturas é a atitude tradicional existente no ensino de literatura, algo que quase sempre é visto como "monótono," "cansativo" e "chato". Aqueles que compartilham dessa visão conservadora insistem em afirmar que os/as alunos/as não gostam de ler e, portanto, não há nenhum sentido em ensinar literatura. Tudo isso além do fato de que as abordagens já referidas em nada contribuem para promover qualquer tipo de mudança neste quadro triste e errôneo.

Um outro fator que reforça o problema diz respeito à formação de nossos/as professores/as - e aqui é onde coloco o foco deste ensaio. Na maioria dos casos, a formação de nossos/as professores/as é conservador e não os/as levará a questionar seu papel em sala de aula, muito menos o papel dos/as alunos/as. O sistema educacional brasileiro parece favorecer totalmente as abordagens cujo centro é o/a professor/a, alguém que acaba por acreditar ser "o mais sábio", "o mais erudito", e que seu conhecimento deve ser enciclopédico e, por essa razão, ele/a é alguém que não deve ser questionado/a e cujo conhecimento "de autoridade" (e autoritário) não deve tolerar a interferência dos/as estudantes. Ronald Carter e Michael Long (1991), ao avaliar professores/as como estes (felizmente a experiência não parece ser um privilégio do Brasil), afirmam que "Deve ter havido professores/as que criaram entre seus/suas aprendizes verdadeira aversão à literatura. Estas são pessoas que poderiam, se expostos a outra forma de ensino, até gostar de literatura, ainda que não enquanto disciplina acadêmica" $\left(\right.$ p.23) ${ }^{3}$

Como já afirmei, a experiência da atitude conservadora no ensino da literatura não é um privilégio nosso. Quando ainda morava na Inglaterra e fazia minha pesquisa de doutorado em literatura, entre 1987 e 1991, fui convidada por Terry Gifford, tutor de PGCE (Curso de Pós-Graduação em

Todas as traduções do inglês para o português são de minha inteira responsabilidade. 
Educação) ${ }^{4}$, em Bretton Hall College/ Universidade de Leeds, a integrar um de seus grupos. Meu interesse ai estava em passar por uma experiência real acerca de um treinamento de professores no Reino Unido, porque minha pesquisa não estava diretamente relacionada ao ensino. Durante um trimestre acadêmico (o ano letivo britânico é dividido em três trimestres de 10 semanas cada), pude participar de discussões, workshops e atividades da oficina de criação literária (sem a pomposidade que o termo representa em português) com o grupo, para assim poder fazer algumas reflexões críticas acerca da formação de professores/as (de língua e literatura) na Inglaterra. O que pude perceber, a partir da experiência, foi que a atitude tradicional em relação ao ensino da literatura é tão velha quanto o tempo, e não importa se você está no Brasil, ou no Japão (havia uma estudante japonesa no grupo), ou na Escócia, ou na Inglaterra, na verdade, em qualquer lugar do mundo, porque as atitudes são praticamente as mesmas. O nó do problema reside no fato de que um treinamento adequado deve provocar professores/as ao questionamento de valores tradicionais e propor valores alternativos. Nesse grupo de PGCE estivemos expostos a pesquisa na área que questionava os valores tradicionais $e$ propunha outros, alternativos. Estes eram, por sua vez, discutidos criticamente e transformados em algo possivel de ser trazido para a sala de aula. Entre os valores que fomos levados a considerar e questionar, havia um que colocava em xeque a posição do/a professor/a em sala de aula. Não somos seres divinos, portanto, devemos descer do nosso pedestal de segurança. Concordo com Brown e Gifford (1989) quando dizem que "[o/a professor/a] não é mais o especialista exegeta derramando interpretações de autoridade para os/as alunos/as. É um/a capacitador/a, questionador/a, apoio e desafiador/a" (p.7). Isso significa que precisamos buscar a vontade de mudar nossas atitudes em relação ao lugar que ocupamos como professores/as no processo de ensino e aprendizagem, em

$\mathrm{Na}$ Inglaterra qualquer pessoa que queira ser professor/a deve passar por um curso de formação que os/as prepare especificamente para a profissào. Não basta apenas ter um curso de graduação. O PGCE corresponderia. aqui no Brasil, a um curso de especialização lato sensu. 
sala de aula, não importando se somos professores de linguas (estrangeiras ou materna) ou de literaturas. Essa mudança necessariamente tem que questionar os valores estabelecidos e propor outros tanto para professores/as quanto para alunos/as. Como bem afirmam Brown e Gifford, o papel do/a professor/a não é o de centro mas o de uma mão que ajuda a guiar, alguém que esteja pronto/a para "encorajar a voz tentativa e hesitante" do/a aluno/a, que é quem deve ser o centro.

É possivel encontrar abordagens alternativas para o ensino de línguas e literaturas? Se assim for, de que maneira podemos romper com mitos e percepções conservadoras dos dois lados? Há colegas, como, por exemplo, Rejane Mendonça (1992), que acreditam só ser possivel, no caso das linguas estrangeiras, unir o ensino de línguas e de literaturas através da estilística. Ou, do lado da literatura, como romper com percepções elitistas e colonialistas que colocam a literatura num alto pedestal (se comparada com o ensino de línguas), só permitindo acesso a ela para pessoas altamente qualificadas, seres divinos que são os únicos abertos a 'transformações', especialmente se produzidas a partir da leitura de textos literários canônicos? Contrariamente a essas visões, defendo uma abordagem que abra e amplie os horizontes de professores/as e alunos/as em busca de um mundo que caiba os dois campos do conhecimento.

A literatura continuará sendo "um negócio chato", como colocam Brumfit e Carter (1987), se respostas diferentes para o ensino não forem dadas. O que pretendo falar a partir de agora diz respeito a como vejo uma possibilidade de mudança para que professores/as possam começar a considerar a literatura como uma fonte de auxílio no ensino das línguas (sejam elas a materna ou as estrangeiras).

O canal da criatividade é uma das respostas mais adequadas quando pensamos o ensino das línguas e das literaturas. A língua, na visão de Brumfit e Carter (1987), é sempre crucial para a literatura, mas a literatura é sempre mais do que língua. Aqui entram elementos da cultura, da ideologia, entre outros, que estão presentes num texto literário e estes podem não ser o centro quando o foco é o ensino das línguas. 
Se pensamos o ensino das línguas estrangeiras, conforme 0 pensamento de Brumfit (1987), as literaturas são um campo de auxílio extremamente fértil. O modelo cultural de outras sociedades tem tudo a ver com o ensino das literaturas; nesse caso, trabalhar a língua da forma como ela é usada numa situação que imita a realidade pode ser proveitoso, especialmente porque contribui para o desenvolvimento pessoal do/a aluno/a, como defendem Carter e Long (1991).

No inicio deste trabalho, falei sobre abordagens desmotivadoras, tais como o uso de textos simplificados de literatura no ensino das linguas estrangeiras. Quero retomar o argumento da literatura como ferramenta para o ensino das linguas porque ele complementa o meu próprio argumento em favor de mudanças. Compartilho com Carter e Long (1991) a visão de que o uso da literatura como um mero instrumento para o ensino de línguas minimiza o papel da literatura no processo de aprendizagem. Este argumento

confunde a natureza da língua na literatura e pode até resultar em atividades mecanicistas e desmotivadoras em vez de um engajamento genuíno com a obra literária e provavelmente terá efeitos danosos [para o/a aluno/a] no sentido de estragar qualquer prazer que um poema ou história poderia ter (p.2).

O uso da literatura no ensino de línguas não pode ser visto meramente como uma ferramenta para se aprender a lingua. Mais do que isso, a língua é um caminho, um método, para o acesso ao texto; além disso, precisa ser vista como uma forma de ajuda pessoal e de divertimento para os/as alunos/as. Se mantemos a visão errônea e preconceituosa de que eles/as não gostam de ler e não estão acostumados/as à leitura, só contribuiremos ainda mais para a sua completa rejeição da literatura.

Abordagens centradas no professor mantêm 0 conhecimento sobre literatura nas mãos dos/as professores/as. Ao invés do conhecimento sobre literatura, a mudança poderia começar com a substituição da preposição. Teríamos então conhecimento de literatura, o que redirecionaria o foco de atenção nas nossas salas de aula para os/as alunos/as, cuja atitude é normalmente a de um bichinho quieto, calado, 
envergonhado e hesitante. Ao transformarmos a abordagem para centrá-la no aluno, o primeiro resultado deverá ser uma mudança na atmosfera da sala de aula: de "chatas" e "cansativas", as aulas podem se tornar prazerosas, e o divertimento certamente será o seu tom principal. Em termos de literatura, a mudança materializar-se-á quando começarmos a usá-la como uma fonte para a aprendizagem da língua. Essa é uma forma legítima e preciosa para ensinar línguas. Significa deixar o estudo da literatura para propósitos acadêmicos para aqueles que queiram aprofundar seu conhecimento sobre literatura. Se usamos uma abordagem para a literatura com base na língua, isso significa mergulhar em processos de leitura que acabarão por levar os/as alunos/as a se tornarem mais ativos e mais participativos nas nossas aulas, além de ajudá-los a ter acesso à literatura de uma forma diferente, que os/as ajudará também quando estiverem lidando com a literatura para propósitos acadêmicos.

Nunca é demais dizer que abordagens tradicionais são muito perigosas no processo de aprendizagem. $O$ uso de textos prontos (simplificados), perguntas detalhadas, tudo isso tende a favorecer o/a professor/a e não o/a aluno/a.

A visão contemporânea de abordagens da literatura (e do ensino em geral) que é compartilhada com a maioria dos/as pesquisadores/as estrangeiros/as na área (Brumfit \& Carter: 1987; Brown \& Gifford: 1989; Rosen: 1989; Carter \& Long: 1991; Gillian Lazar: 1993; Carter: 1997, entre outros/as) ${ }^{5}$ apontam para abordagens centradas no/a aluno/a porque isto implica em explorar e compartilhar idéias, sentimentos e atitudes acerca dos textos estudados. O papel do/a professor/a é o de um/a iniciador/a do processo. Para mim, o processo de ensino/aprendizagem é uma via de mão dupla, e compartilhar responsabilidades é uma boa forma de começar a motivar nossos/as alunos/as não apenas para aprender a língua

No Brasil eu citaria pesquisadores/as como Lynn Mário, da USP; Rosalba Ramalho Vieira, da UFSC/Unicamp; Sônia Zyngier, da UFRJ; Rita M.D. Zozzoli, da UFAL, entre outros/as que pesquisam nesta área. A publicação a sair em breve pela Revista Ilha do Desterro da PG em Inglês da UFSC, por mim organizada, reúne artigos destes/as pesquisadores/as, tratando exatamente do ensino de lingua e literatura. 
através da literatura, mas também para aprender que, enquanto indivíduos, eles/as são responsáveis pela forma como aprendem alguma coisa - seja literatura, língua, ou qualquer outro assunto. Brown e Gifford (1989) defendem a idéia que

Quanto mais responsabilidades oferecemos aos/às alunos/as quanto mais eles/as passam a conhecer as exigencias que fazemos deles/as ... Uma forma de encorajar mais participação é delegar tarefas para que o/a aluno/a passe a fazer um papel mais central e também compartilhe nossos pensamentos sobre ensino e aprendizagem (p.41).

Acredito que a maioria de nós sofreu por ter tido professores/as de literatura (ou outras disciplinas) que pensavam saber tudo e, por isso, nossas visões acerca de um determinado texto não significava absolutamente nada. Esta é a minha própria experiência enquanto aluna de graduação na UFPB, em João Pessoa; é também o testemunho dos meus alunos aqui na UFAL, quando falam da sua impotência (e raiva) diante de professores/as que colocam perguntas irrespondiveis de propósito, apenas para transformá-los/as em alunos estúpidos e idiotas. Este tipo de professor/a não tem o mínimo respeito pelos/as seus/suas alunos/as e acredita em seu poder como a única razão para ensinar. Para mim está claro que perguntas "quilométricas" não ajudarão aos/às alunos/as a compreender um texto ou tornar-se mais fluente na língua que aprende. Carter \& Long (1991) dizem que "O/A professor/a deve decidir qual o processo mais apropriado para tornar um texto mais acessivel e, óbvio, não deve tentar impor sua própria interpretação do texto aos/às alunos/as como sendo "correta"' (p.27). Devido à nossa formação, nós professores/as somos levados/as a pensar o/a aluno/a como tabula rasa e tentar impor nosso conhecimento e poder sobre os/a alunos/as. Isso é um erro grave que precisamos apagar de nossas mentes. A teoria do "jug and mug" (Rosen: 1989) ${ }^{6}$ é perigosa porque assume

A teoria do "jug and mug" de Michael Rosen (1989) tem paralelos com a "concepção bancária" da educação de Paulo Freire (1979). Resumidamente, na teoria do "jug and mug", o professor é o dono do conhecimento (literalmente uma "jarra" cheia), o qual passa para o aluno (que é a "caneca" vazia, pronta a receber). 
que o/a professor/a sabe tudo. Pensando na literatura (ou em qualquer outro assunto), nossas visões sobre um texto podem estar corretas, mas precisamos aprender a respeitar o entusiasmo dos/as alunos/as em fazer sua voz ouvida, ainda que sua opinião seja ingênua e infantil. Nunca dizer que algo é 'errado', como nos ensina Rosen (1989): "Rotular o que as pessoas dizem como 'errado', 'ininteligível' e 'indesejável' é o mesmo que rotular individuos e grupos sociais de 'errados', 'ininteligiveis' e 'indesejáveis'” (p.70).

Tudo que dizemos faz parte do cenário social e psicológico. Uma afirmação que avalia negativamente o que um/a aluno/a diz pode ter o poder de um enorme impacto no sentido de desmotivá-lo/a e fechar de uma vez a porta do aprendizado e do gostar de literatura. As interpretações, quando vistas dentro de seus contextos, têm que ser aceitas, pois são válidas e devem ser respeitadas.

O/A professor/a, se no centro do conhecimento, não pergunta, exige. É diferente do/a professor/a cujo papel é de tutor/a: ele/a intervém e supervisiona. Maley e Duff (1991) pensam que na aprendizagem da língua estrangeira, por exemplo, o uso da lingua materna é bastante útil. Afirmam ainda que o uso da literatura como brincadeira tem um componente de troca e intercâmbio com o texto estudado. Auxilia o teste e a exploração dos seus limites. A língua materna pode até mesmo ser usada como fonte de auxilio para os/as alunos/as lidarem com certos temas. Carter e Long (1991) dizem que "o/a aluno/a de uma segunda literatura deve ser incentivado/a a ler mais e usar a experiência para fazer comparações e marcar contrastes" (p.49).

Portanto, aprender língua a partir da literatura significa introduzir um processo de divertimento e prazer no contexto do ensino. A literatura não deve jamais ser vista como um obstáculo no processo de aprendizagem de uma língua. Pelo contrário, significa acesso a ela, especialmente porque a aprendizagem deve ser vista como um processo produtivo onde alunos/as tanto brincam quando levam a sério a aprendizagem. 


\section{REFERÊNCIAS BIBLIOGRÁFICAS}

BROWN, John; Gifford, Terry. Teaching A Level English Literature - a Student-Centred Approach. London: Routledge, 1989.

BRUMFIT, C. J.; CARTER, R. A. Literature and Language Teaching. Oxford: OUP, 1987.

CARTER, Ronald; LONG, Michael. Teaching Literature. Essex: Longman, 1991.

CARTER, Ronald; LONG, Michael. The Web of WordsExploring Language through Literature. Cambridge: CUP, 1995.

CARTER, R. Investigating English Discourse: Language, Literacy and Literature. London: Routledge, 1997.

CASHDAN, Liz (Ed.). Writing in Education. The Magazine of the National Association of Writers in Education. York, Issue n.5, Spring 1995.

MALEY., Alan; DUFF, Alan. The Inward Ear - Poetry in the Language Classroon. Cambridge: CUP, 1989.

MENDONÇA, Rejane Vidal de. Language and Literature: a Never Ending Dispute? Past Present and Future. n.7, p. 17-19, Jan. 1992.

ROSEN, Mike. Did I Hear You Write? London: André Deutsch Limited, 1998.

WIDDOWSON, H. Stylistics and the Teaching of Literature. London: Longman, 1978.

WILLEY, George; DUNK, Mary. Integrated English - a Course in English Language and Literature. Cambridge: CUP, 1985. 